\title{
Recent insights into the biological roles of mucin-type O-glycosylation
}

\author{
E Tian • Kelly G. Ten Hagen
}

Received: 11 April 2008/Accepted: 12 June 2008 / Published online: 10 August 2008

(C) The Author(s) 2008

\begin{abstract}
In this special issue of the Glycoconjugate Journal focusing on glycosciences and development, we summarize recent advances in our understanding of the role of mucintype O-glycans in development and disease. The presence of this widespread protein modification has been known for decades, yet identification of its biological functions has been hampered by the redundancy and complexity of the enzyme family controlling the initiation of O-glycosylation, as well as the diversity of extensions of the core sugar. Recent studies in organisms as diverse as mammals and Drosophila have yielded insights into the function of this highly abundant and evolutionarily-conserved protein modification. Gaining an understanding of mucin-type O-glycans in these diverse systems will elucidate crucial conserved processes underlying many aspects of development and homeostasis.
\end{abstract}

Keywords Glycosylation - O-glycosylation .

Development $\cdot$ Mucin $\cdot$ Disease

$\begin{array}{ll}\text { Abbreviations } & \\ \text { ppGaNTase or } & \text { UDP-GalNAc:polypeptide } \\ \text { ppGalNAcT or pgant } & N \text {-acetylgalactosaminyltransferase } \\ \text { GalNAc } & N \text {-acetylgalactosamine } \\ \text { Gal } & \text { galatose } \\ \text { GlcNAc } & N \text {-acetylglucosamine } \\ \text { GlcA } & \text { glucuronic acid }\end{array}$

E Tian $\cdot$ K. G. Ten Hagen $(\bowtie)$

Developmental Glycobiology Unit, NIDCR,

National Institutes of Health,

Building 30, Room 426, 30 Convent Drive, MSC 4370,

Bethesda, MD 20892-4370, USA

e-mail: Kelly.Tenhagen@nih.gov

\section{Introduction}

Proteins are decorated with a variety of carbohydrate side chains that are responsible for mediating many diverse cellular and developmental events (reviewed in [1]). The two major forms of protein glycosylation found in eukaryotes are $\mathrm{N}$-linked and O-linked, designated as such by virtue of their glycosidic linkage to the corresponding amino acid. While many types of O-glycosylation are known to occur, the most abundant is mucin-type Oglycosylation, which involves the addition of an $\mathrm{N}$-acetylgalactosamine residue (GalNAc) to the hydroxyl group of either serine or threonine to form the Tn antigen ( $\mathrm{Tn} \mathrm{Ag}$ ) (GalNAc $\alpha 1-\mathrm{S} / \mathrm{T})$ (Fig. 1). This type of glycosylation is evolutionarily conserved, being found in mammals down to certain types of fungi $[2,3]$. Here, we describe the enzymes responsible for the synthesis of the most common mucintype O-glycans and focus on recent advances in our understanding of their diverse biological roles.

\section{Enzymes responsible for the synthesis of mucin-type O-glycans}

O-glycosylation is initiated by a family of enzymes

Mucin-type O-linked glycosylation is initiated by a family of enzymes known as the UDP- $N$-acetylgalactosamine: polypeptide $\mathrm{N}$-acetylgalactosaminyltransferases (ppGalNAcTs or ppGaNTases in mammals and PGANTs in Drosophila; EC 2.4.1.41) (reviewed in [2, 3]) which are responsible for catalyzing the transfer of GalNAc from the nucleotide sugar UDP-GalNAc to the hydroxyl group of either serine or threonine in protein substrates destined to 
a Mammalian mucin-type 0-glycan synthesis

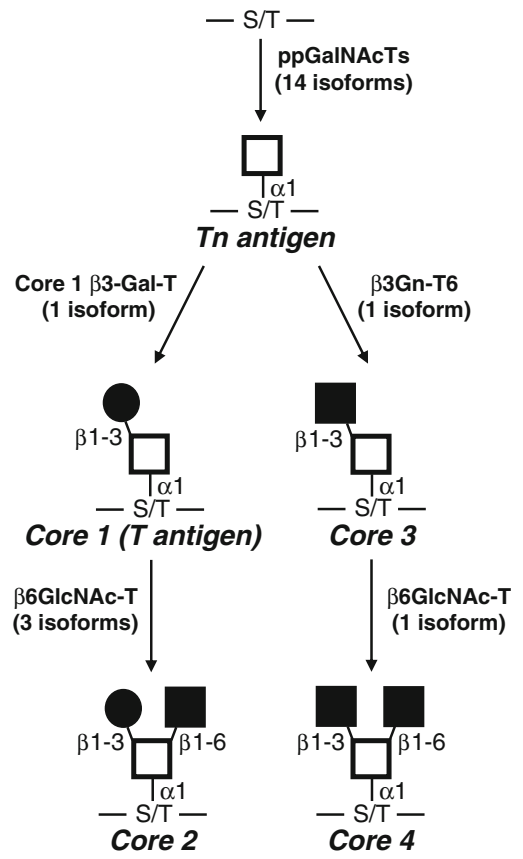

Fig. 1 Biosynthesis of the most common mucin-type O-glycans in mammals (a) and Drosophila melanogaster (b). The initiation of mucin-type O-glycosylation is catalyzed by the addition of GalNAc onto the hydroxyl group of either serine or threonine in protein substrates destined to be membrane-bound or secreted, forming the Tn antigen ( $\mathrm{Tn}$ $\mathrm{Ag}$ ). Enzymes responsible for the synthesis of core 1 (T antigen), core 2, core 3 and core 4 structures are shown. Additional extensions of

be membrane-bound or secreted (Fig. 1). There are 15 reports of distinct mammalian ppGalNAcTs in the literature, 14 of which have been functionally characterized (reviewed in $[2,3]$ ) (Table 1). There is now evidence for three additional active isoforms, with homology searches revealing the potential for a total of 20 isoforms in human and 18 isoforms in mouse (J. Raman, T. Fritz and L. A. Tabak, personal communication). Fewer family members are found in the Drosophila and C. elegans; thus far, the fly has nine functional transferases (derived from nine distinct genes), with as many as 12 genes total [4-6]; the worm has five cDNAs that encode functional transferases (derived from four genes), with as many as nine transferaseencoding genes total [7, 8]. All isoforms are type II transmembrane proteins with a short N-terminal cytoplasmic region, a hydrophobic transmembrane region, a variable length stem region and a conserved catalytic region. Biochemical analyses have revealed unique as well as overlapping substrate preferences amongst isoforms [4, 5, 9-14] (reviewed in [2]). Additionally, there is a hierarchy of action within this family, with certain members acting as "initiating" transferases, transferring GalNAc to unmodified substrates, while other members act only on previously b Drosophila mucin-type O-glycan synthesis

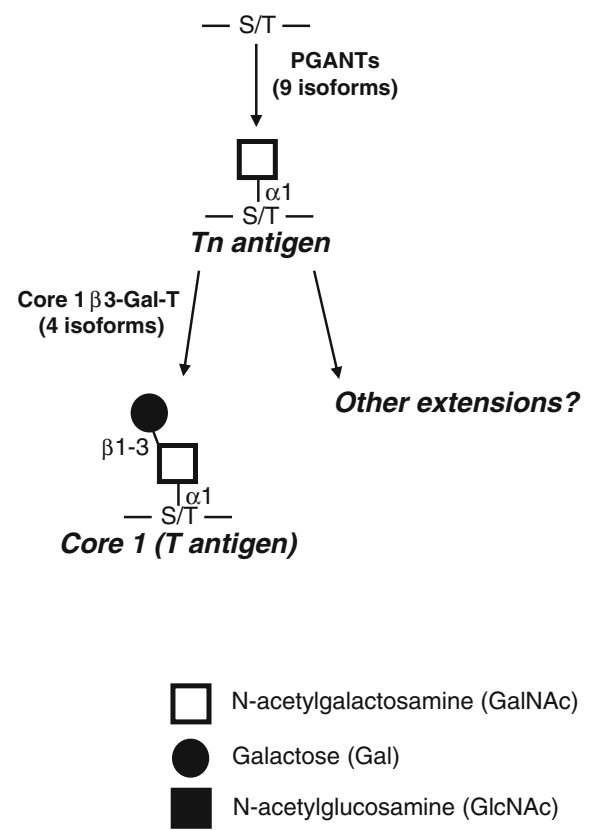

mammalian O-glycans and modifications with sialic acid or fucose are not shown. There is currently no evidence for sialylated O-glycans in Drosophila. ppGalNAcTs or PGANTs, UDP-N-acetylgalactosamine: polypeptide $\mathrm{N}$-acetylgalactosaminyltransferases; Core $1 \beta 3-\mathrm{Gal}-\mathrm{T}$, core $1 \beta 1$-3-galactosyltransferase; $\beta 3 \mathrm{Gn}-\mathrm{T} 6, \beta 1-3 \mathrm{~N}$-acetylglucosaminyltransferase; $\beta 6 \mathrm{GlcNAc}-\mathrm{Ts}, \beta 1-6 \mathrm{~N}$-acetylglucosaminyltransferase

glycosylated substrates ("glycopeptide transferases") [15-18].

Phylogenetic analysis reveals a high degree of sequence conservation among ppGalNAcTs across species, defining orthologous groups or pairs $[4,5]$. These orthologues display not only sequence conservation but functional conservation as well. In vitro studies revealed that orthologues share similar substrate preferences $[4,5]$ and preferred sites of GalNAc addition within those substrates [4]. This functional conservation suggests unique biological roles for members of this family that have been maintained over the course of evolution.

Studies examining the expression of each family member revealed unique spatial and temporal gene expression patterns during both mammalian and fly development $[6,19]$. Some members are expressed widely in many tissues during many stages of development while others are expressed in a very restricted subset of tissues at specific times [6, 19]. Collectively, the unique spatial and temporal expression patterns, along with conserved substrate preferences and hierarchy of action within this family suggest a complex and highly regulated process governing the acquisition of mucin-type O-glycans. 
Table 1 Published reports of mammalian ppGalNAcTs

\begin{tabular}{|c|c|c|c|}
\hline ppGalNAcT isoform & Species & Activity demonstrated? & Reference \\
\hline ppGalNAc-T1 & Bovine & Yes & Homa et al. [83], Hagen et al. [84] \\
\hline ppGalNAc-T1 & Rattus norvegicus & Yes & Hagen et al. [85] \\
\hline ppGalNAc-T1 & Homo sapiens & Yes & White et al. [86] \\
\hline ppGalNAc-T1 & Mus musculus & Yes & Hagen et al. [87] \\
\hline ppGalNAc-T1 & Porcine & Yes & Yoshida et al. [88] \\
\hline ppGalNAc-T2 & Homo sapiens & Yes & White et al. [86] \\
\hline ppGalNAc-T3 & Homo sapiens & Yes & Bennett et al. [89] \\
\hline ppGalNAc-T3 & Mus musculus & Yes & Zara et al. [9] \\
\hline ppGalNAc-T4 & Mus musculus & Yes & Hagen et al. [87] \\
\hline ppGalNAc-T4 & Homo sapiens & Yes & Bennett et al. [90] \\
\hline ppGalNAc-T5 & Rattus norvegicus & Yes & Ten Hagen et al. [13] \\
\hline ppGalNAc-T6 & Homo sapiens & Yes & Bennett et al. [10] \\
\hline ppGalNAc-T7 ${ }^{\mathrm{a}}$ & Rattus norvegicus & Yes & Ten Hagen et al. [15] \\
\hline ppGalNAc-T7 & Homo sapiens & Yes & Bennett et al. [16] \\
\hline ppGalNAc-T $8^{\mathrm{b}}$ & Homo sapiens & No & White et al. [91] \\
\hline ppGalNAc-T9 & Homo sapiens & Yes & Toba et al. [92], Zhang et al. [93] \\
\hline ppGalNAc-T10 ${ }^{\mathrm{c}}$ & Rattus norvegicus & Yes & Ten Hagen et al. [17] \\
\hline ppGalNAc-T10 & Homo sapiens & Yes & Cheng et al. [94] \\
\hline ppGalNAc-T11 & Homo sapiens & Yes & Schwientek et al. [5] \\
\hline ppGalNAc-T12 & Homo sapiens & Yes & Guo et al. [95] \\
\hline ppGalNAc-T13 ${ }^{\mathrm{d}}$ & Mus musculus & Yes & Hennet et al. [96], Zhang et al. [93] \\
\hline ppGalNAc-T13 & Homo sapiens & Yes & Zhang et al. [93] \\
\hline ppGalNAc-T14 & Homo sapiens & Yes & Wang et al. [97] \\
\hline ppGalNAc-T15 & Homo sapiens & Yes & Cheng et al. [98] \\
\hline
\end{tabular}

${ }^{\text {a }}$ Originally designated -T6 but renamed -T7 in a note added in proof

${ }^{\mathrm{b}}$ No confirmation of biochemical activity to date

${ }^{c}$ Originally designated -T9 but renamed -T10

${ }^{\mathrm{d}}$ Originally designated -T8 but renamed -T13

(there is evidence for five additional human isoforms, three of which have confirmed transferase activity; J. Raman, T. Fritz and L. A. Tabak, personal communication)

\section{Extension of the GalNAc $\alpha 1-\mathrm{S} / \mathrm{T}$}

The most abundant modification of the core GalNAc $\alpha 1-\mathrm{S} / \mathrm{T}$ is known as the core 1 or $\mathrm{T}$ antigen structure $(\mathrm{Gal} \beta 1$ 3 GalNAc $\alpha 1-\mathrm{S} / \mathrm{T}$ ) (Fig. 1). There is one core $1 \beta 1-3$ galactosyltransferase (core $1 \beta 3-\mathrm{Gal}-\mathrm{T}$ ) in mammals responsible for the addition of a galactose in a $\beta 1-3$ linkage to GalNAc [20, 21]; the gene encoding this enzyme is widely expressed in mammals, especially in the liver, kidney, heart and placenta $[20,21]$. This gene is evolutionarily-conserved, with one core $1 \beta 3$-Gal-T being functionally described in $C$. elegans [22] and at least four functional core $1 \beta 3-G a l-T s$ described in Drosophila [23]. Like its mammalian counterpart, the C. elegans core $1 \beta 3-G a l-T$ gene is expressed throughout all developmental stages and in all cells, suggesting a crucial requirement for this modification [22]. The complete developmental expression pattern of the multiple Drosophila core $1 \beta 3$-Gal-T genes is not currently known, although two are expressed in the developing salivary glands and one is expressed in the amnioserosa, a tissue involved in cell migration and adhesion during development [23]. Interestingly, the activity of the mammalian core
$1 \beta 3$-Gal-T enzyme requires the coexpression of a molecular chaperone, Cosmc [24]. Cosmc aids in folding and stability of the core $1 \beta 3$-Gal-T enzyme, ensuring proper localization to the Golgi apparatus $[24,25]$. Mutations in Cosmc result in the loss of core $1 \beta 3$-Gal-T from the Golgi apparatus and loss of core 1 activity $[24,25]$. In contrast to the mammalian enzyme, the $C$. elegans and Drosophila core $1 \beta 3-G a l-T s$ do not appear to require a chaperone for activity $[22,23]$.

The core 3 modification (GlcNAc $\beta 1-3$ GalNAc $\alpha-\mathrm{S} / \mathrm{T}$ ) is catalyzed by the $\beta 1-3 \quad N$-acetylglucosaminyltransferase ( $\beta 3 \mathrm{Gn}-\mathrm{T} 6)$ (Fig. 1). There is one $\beta 3 \mathrm{Gn}-\mathrm{T} 6$ in mammals that is expressed primarily in stomach, small intestine and colon $[26,27]$. Orthologues responsible for synthesizing the core 3 structure have not been identified in C. elegans or Drosophila as yet.

The core 2 and core 4 O-glycan branching (Fig. 1) of the core 1 and core 3 structures, respectively, is catalyzed by the $\beta 1-6 \mathrm{~N}$-acetylglucosaminyltranferases ( $\beta 6 \mathrm{GlcNAc}-\mathrm{Ts}$ ). There are three core 2 transferases identified to date in mammals [28-32] (reviewed in [33]), two of which catalyze the formation of core 2 structures and one that is responsible for forming both core 2 and core 4 branched 
structures (Fig. 1). The expression pattern of each gene is distinct, suggesting unique biological roles for each enzyme. The T-1 isoform is expressed ubiquitously [28], while T-2 (which is responsible for core 2 and core 4 synthesis) is expressed in the kidney, pancreas, stomach, intestines and colon [30, 31]; T- 3 is expressed in the thymus and $\mathrm{T}$ cells [32], Less is known about the existence of $\beta 6 \mathrm{GlcNAc}-T s$ responsible for this branched structure in $C$. elegans or Drosophila. Thus far no functional $\beta 6 \mathrm{GlcNAc-}$ Ts have been identified in Drosophila but a gene homologous to $\beta 6 \mathrm{GlcNAc}-\mathrm{T}$ has been identified in $C$. elegans (gly-1) [34]. It is of note that no mucin-type O-glycans carrying the core 2 , core 3 or core 4 structures or sialic acid were detected in a recent mass spectroscopy analysis of Drosophila O-glycans [35]. However, evidence for the presence of glucuronic acid (GlcA) on the core 1 O-glycans of Drosophila (M. Tiemeyer, personal communication) and C. elegans has been reported [36]. Additionally, novel O-linked structures containing $\beta$-Glc are also observed in C. elegans [36].

Each of the above mentioned branches can be further extended by the addition of Gal and GlcNAc and further modified by fucosylation and sialylation. The enzymes responsible for these additional modifications and other core structures will not be discussed in this review.

\section{O-glycan function}

\section{O-glycosylation during development}

A crucial role for mucin-type O-glycans during development was first demonstrated in Drosophila. Mutations in one member of the pgant family (pgant $35 \mathrm{~A}$ ) were shown to abrogate enzymatic activity and result in recessive lethality, with death occurring throughout development [5, 37]. This was the first example that mucin-type O-glycans were required for viability in any organism.

Studies of mice deficient for the core $1 \beta 3-G a l-T$ gene ( $T$ syn-/-), provided more detailed information regarding the role of O-glycans in specific organ systems during development $[38,39]$. T-syn-/ - mice displayed defective angiogenesis and died from fatal brain hemorrhages by embryonic day 14 (E14) [38]. Specifically, vasculature formation was irregular in these mice, displaying distorted capillary lumens, and detachment of endothelial cells from periocytes and the extracellular matrix. These studies revealed a role for $\mathrm{O}$ glycans in vascular system/tubular system development, possibly via influencing cell-cell and/or cell-ECM interactions required for proper tube/diffusion barrier formation.

Studies examining hypomorphic mutations in the core 1 $\beta 3-G a l-T$ gene provided additional evidence for the role of O-glycans in tubular architecture and function [39]. In this study, most core $1 \beta 3$-Gal-T hypomorphic mice died within 200 days due to compromised renal function. The kidneys of these mice displayed distorted glomeruli and proximal tubules. The authors propose that the improper glycosylation of podocalyxin (podx1), a glycoprotein normally present on the surface of the renal podocyte foot process is responsible for the disruption in kidney function. podx 1 $-/$ mice die embryonically, with defective kidney formation [40], lending support for the role of this glycoprotein in the defects seen in the core $1 \beta 3$-Gal-T hypomorph. The molecular nature of how the O-glycans on podx 1 are mediating these biological effects remains to be determined but it is suggested to be due to cell adhesion defects [39].

The core $1 \beta 3$-Gal-T hypomorphic mice also displayed thrombocytopenia [39]. The authors propose that abnormal glycosylation of $\mathrm{GpIb} \alpha$, a protein present on platelets and involved in platelet adhesion and function, is responsible for the thrombocytopenia observed. It is also possible that loss of the core 1 structure may result in self-reactivity and clearance of those cells now displaying the $\mathrm{Tn} \mathrm{Ag}$ (see $\mathrm{Tn}$ syndrome below).

Additional evidence for the specific role for O-glycans in tubulogenesis was further supported by recent work in Drosophila. Examination of O-glycans present during Drosophila development revealed an abundance along the apical and luminal regions of developing tubular organs (Fig. 2) [41]. O-glycans detected by lectins and antibodies were present along the apical surfaces of the developing hindgut, foregut, salivary glands, malpighian tubules (the functional equivalent of the kidney) and the tracheal system [41]. Mutations in one member of the pgant family in Drosophila (pgant35A) resulted in abnormal tracheal tube formation. Specifically, tracheal tubes of mutants showed loss of apical and luminal O-glycans and were irregular in diameter and shape (Fig. 3) [42]. Further examination revealed a loss of apicobasal polarity and diffusion barrier formation in the pgant $35 \mathrm{~A}$ mutants. An increase in cytoplasmic vesicular staining of proteins destined for the apical and luminal surfaces was also seen in the mutants [42]. Based on these results, it was proposed that O-glycosylation is responsible for proper apical/luminal composition, apicobasal polarity and diffusion barrier formation in the tracheal system by influencing the apical delivery of proteins/ glycoproteins [42]. Roles for O-glycans in trafficking, delivery and/or maintenance of proteins at the cell surface has also been suggested previously in a number of cell culture studies [43-49]. Taken together, these studies suggest a conserved role for O-glycans in the molecular events governing tubulogenesis across diverse organ systems and species, possibly by influencing trafficking and stability of crucial proteins involved in tube architecture and function.

Most recently, studies in Xenopus have implicated mucintype O-glycosylation in TGF- $\beta$ signaling during develop- 

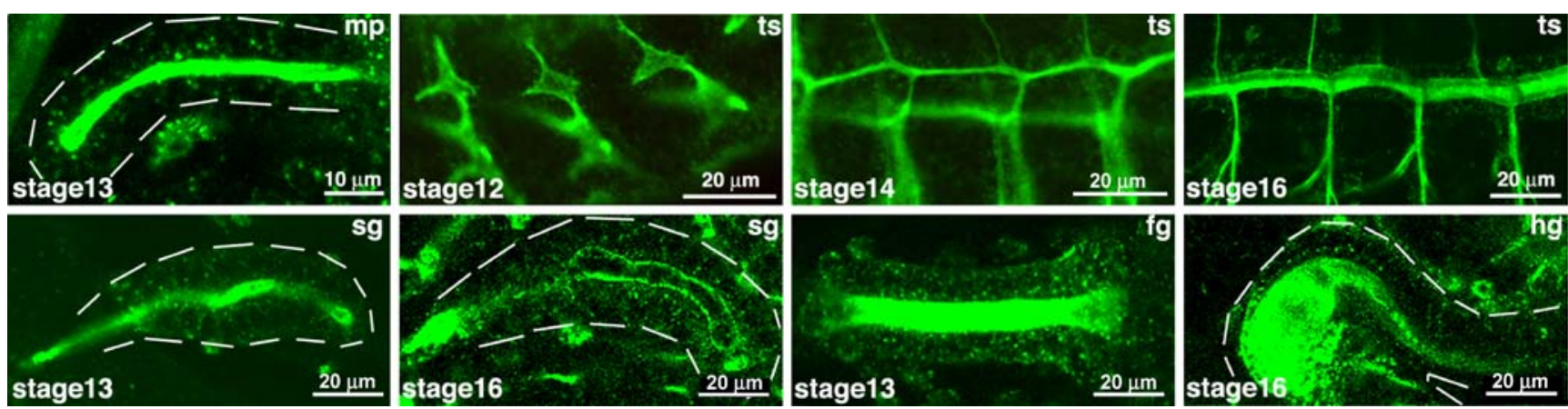

Fig. 2 Tn antigen (GalNAc $\alpha-S / T)$ expression in developing tubular tissues during Drosophila embryogenesis. The dashed white lines outline the outer boundaries of each organ shown. Note the intense apical and luminal presence of the O-glycans in each organ. Stages are

shown in the lower left corner of each panel. $f g$ foregut, $h g$ hindgut, $m p$ malpighian tubules, $s g$ salivary gland, $t s$ tracheal system. Adapted from Glycobiology, 17, 820-827 (2007) by copyright permission of the Oxford University Press

ment [50]. This study demonstrated that over-expression of a putative ppGalNAcT caused inhibition of both Activin and BMP signaling during Xenopus embryogenesis. The authors propose that putative O-glycans on the ActR-IIB receptor may be responsible for the effects seen, by influencing the formation of heteromeric receptor complexes. However, direct demonstration of transferase activity, as well as the receptors, ligands or other proteins that are normally O-glycosylated in vivo remains to be determined.

\section{O-glycosylation and disease}

Recently studies have highlighted the involvement of mucin-type O-glycosylation in a number of diseases. One such example is familial tumoral calcinosis, a recessively inherited condition characterized by hyperphosphatemia, increased bone density and the development of ectopic calcified masses [51]. Studies of affected families revealed that this disease is the result of mutations in the glycosyltransferase ppGalNAc-T3 [51-53]. In other affected groups, mutations in the phosphate-regulating hormone FGF23 cause the same condition [54], suggesting a link between FGF23 and O-glycosylation. Patients with mutations in ppGalNAc-T3 have increased levels of cleaved, inactive FGF23 and a paucity of intact, active FGF23 in their blood $[52,55]$. In vitro studies have demonstrated that ppGalNAc-T3 can glycosylate FGF23 at a serine near a protease cleavage site, leading to the hypothesis that $\mathrm{O}-$ glycans normally present on FGF23 confer protection from proteolysis and aid in the proper secretion of intact FGF23 [56]. In the case of ppGalNAc-T3 mutations, it is proposed that under-glycosylated FGF23 is prematurely cleaved and inactivated, leading to improper regulation of phosphate levels and the resultant phenotypic consequences in patients. These data suggest a role for O-glycans in regulating proteolytic events necessary for proper phosphate regulation and homeostasis in vivo.

Additional evidence for the role of O-glycans in disease comes from examining the molecular basis of Tn syndrome, a rare autoimmune disorder that results in thrombocytopenia and hemolytic anemia [57]. Mutations in Cosmc (the chaperone for the core $1 \beta 3-G a l-T$ ) were shown to be responsible for Tn syndrome in a subset of hematopoetic cells [24]. Somatic mutations in Cosmc result in the loss of the core 1 structure on a subpopulation of hematopoetic cells, exposing the immunoreactive Tn Ag on these cells and thus leading to hemolysis.

IgA nephropathy (IgAN) is also thought to have its root in aberrant O-glycosylation. This disease is characterized by abnormal deposition of IgA1 in the glomerular mesangium, resulting in glomerulonephritis (reviewed in [58]). IgA1 is normally heavily O-glycosylated in the hinge region with sialylated core 1 structures [59-62]. However, mesangial IgA1 in IgAN patients is aberrantly O-glycosylated, showing a loss of the core 1 structure [60, 61, 63-66]. It is thought that the truncated O-glycans present on IgA1 can cause aggregation of these molecules, forming $\operatorname{IgA}$ immune complexes that would promote glomerular inflammation. Current studies are focused on identifying the molecular basis for the changes in IgA O-glycosylation. While decreased Cosmc gene expression in IgAN patients has been reported by one group [67], another study failed to find a significant difference in core $1 \beta 3$-Gal-T or Cosmc enzymatic activity or gene expression [68]. Thus far, mutations in the genes responsible for core 1 formation have not been found in patient populations, suggesting that the primary defect may reside in another component of the O-glycosylation machinery.

Recent genome-wide association studies cataloguing loci that influence plasma lipid levels in humans have identified a ppGalNAcT (ppGalNAc-T2 or GALNT2) as one of a number of genes associated with variations in high density lipoprotein (HDL) levels [69, 70]. ppGalNAc-T2 variants may contribute to the heritable component of lipid profiles by glycosylating proteins involved in lipid metabolism, 

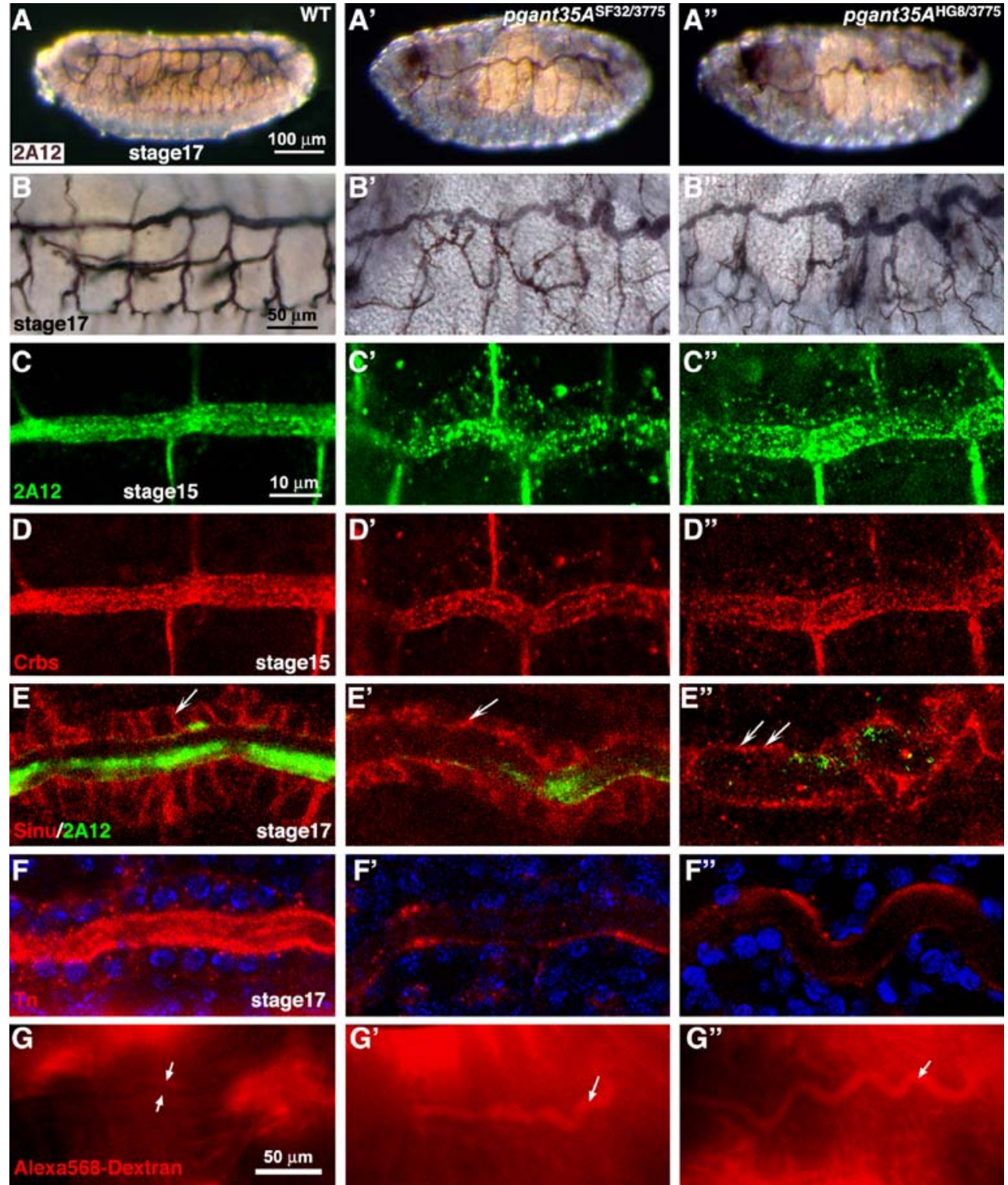

Fig. 3 A PGANT O-glycosyltransferase is required for proper tracheal development and diffusion barrier formation during Drosophila embryogenesis. Wild-type $(A-G)$, pgant $35 A^{\mathrm{SF} 32 / 3775}\left(A^{\prime}-G^{\prime}\right)$, pgant $35 A^{\mathrm{HG} 8 / 3775}\left(A^{\prime \prime}-G^{\prime \prime}\right)$. (A) Tracheal luminal marker 2A12 staining shows the normal development of the tracheal system in wild type (WT) embryos at stage 17 and abnormal tracheal tube formation at stage 17 for pgant $35 A^{\mathrm{SF} 32 / 3775}\left(A^{\prime}\right)$ and pgant35 $A^{\mathrm{HG} 8 / 3775}\left(A^{\prime \prime}\right)$ homozygous maternal/zygotic $(\mathrm{m} / \mathrm{z})$ mutants. Magnified views $(\times 40)$ are shown for wild type $(B)$, pgant $35 A^{\mathrm{SF} 32 / 3775}\left(B^{\prime}\right)$ and pgant $35 A^{\mathrm{HG} 8 / 3775}$ $\left(B^{\prime \prime}\right) \mathrm{m} / \mathrm{z}$ mutants. Tracheal staining with the luminal marker $2 \mathrm{~A} 12$ (green) at stage 15 in pgant $35 A^{\mathrm{SF} 32 / 3775}\left(C^{\prime}\right)$ and pgant $35 A^{\mathrm{HG} 8 / 3775}\left(C^{\prime \prime}\right)$ $\mathrm{m} / \mathrm{z}$ mutants reveals decreased luminal staining and increased cytoplasmic staining relative to wild type (WT) $(C)$. Similar results are seen with Crbs staining at stage 15 in WT $(D)$, pgant35 $A^{\mathrm{SF} 32 / 3775}\left(D^{\prime}\right)$ and pgant $35 A^{\mathrm{HG} 8 / 3775}\left(D^{\prime \prime}\right) \mathrm{m} / \mathrm{z}$ mutants. At stage 17, the septate junction protein, Sinuous (Sinu), is mislocalized in the pgant $35 \mathrm{~A} \mathrm{~m} / \mathrm{z}$ mutant

potentially influencing their stability or function. If verified, future therapeutics to regulate lipid levels and treat cardiovascular disease may include those directed at $\mathrm{O}$ linked glycosylation. trachea $\left(E^{\prime}\right.$ and $\left.E^{\prime \prime}\right)$ relative to wild type $(E)$, as the mutants show reduced lateral localization and increased apical distribution (arrows in panels $\left.E-E^{\prime \prime}\right)$. Tn Ab staining in the apical and luminal regions of the trachea of stage 17 embryos $\left(F-F^{\prime \prime}\right)$ is lost in pgant $35 A^{\mathrm{SF} 32 / 3775}\left(F^{\prime}\right)$ and pgant $35 A^{\mathrm{HG} 8 / 3775}\left(F^{\prime \prime}\right) \mathrm{m} / \mathrm{z}$ mutants relative to wild type $(F)$. Stage 1617 embryos were injected with $10 \mathrm{kD}$ dextran dye and visualized after $30 \mathrm{~min}$. Wild type embryos showed no dye leakage into the tracheal system (between arrows in $G$ ), whereas pgant $35 A$ homozygous $\mathrm{m} / \mathrm{z}$ mutants had significant dye present in the tracheal tubes (arrows in $G^{\prime}$ and $G^{\prime \prime}$ ), indicating loss of paracellular diffusion barrier formation. Scale bar: $100 \mu \mathrm{m}$ for $A-A^{\prime \prime} ; 50 \mu \mathrm{m}$ for $B-B^{\prime \prime} ; 10 \mu \mathrm{m}$ for $C-F^{\prime \prime} ; 50 \mu \mathrm{m}$ for $G-$ $G^{\prime \prime}$. Embryos are oriented such that anterior is to the left and dorsal is $u p$. Adapted from The Journal of Biological Chemistry, 282, 606-614 (2007) by copyright permission of The American Society for Biochemistry and Molecular Biology, Inc

Finally, the association between altered glycosylation patterns and tumor formation is well documented [71-74]. Recent studies have begun to directly interrogate this relationship by altering the activity of the glycosyltransfer- 
ase responsible for the synthesis of the core 3 structure. In one study where $\beta 3 \mathrm{Gn}-\mathrm{T} 6$ activity was found to be downregulated in colon carcinomas, overexpression of $\beta 3 \mathrm{Gn}-\mathrm{T} 6$ in these cells decreased their metastatic ability [75]. In another study, mice deficient in the $\beta 3 \mathrm{Gn}$-T6 gene showed an increase in intestinal barrier permeability and became highly susceptible to induced colitis and colorectal tumors [76]. This study not only further supports the role of Oglycans in proper diffusion barrier function, but suggests that a causal role exists between loss of normal Oglycosylation patterns and tumor formation/progression.

\section{O-glycosylation and the immune system}

Many studies in mice have highlighted the importance of diverse types of glycans in immune system function. Here, we highlight recent work involving the deletion of specific glycosyltransferases involved in mucin-type O-glycan biosynthesis. Mice deficient in one of the core 2 transferases (Core2GlcNAcT-1) displayed altered inflammatory responses combined with decreased neutrophil infusion [77, 78]. Leukocytes from these mice displayed decreased rolling on P-, E- and L-selectin [78], highlighting a role for core 2 Oglycans in selectin adhesion as it relates to immune cell function. Likewise, deletion of a glycosyltransferase that extends the core 1 structure (Core1- $\beta 3$ GlcNAcT) as well as double mutants of Core1- 33 GlcNAcT and Core2GlcNAcT-1 displayed reduced lymphocyte homing, although compensation was provided by selectin ligands present on N-glycans as well [79]. Work by a number of groups has also demonstrated the importance of fucosylation [80] and sialylation [81], two common modifications found on mucin-type O-glycans, in lymphocyte homing and homeostasis, respectively.

Recent work examining mice deficient in a member of the initiating ppGalNAcT family (ppGalNAc-T1) has demonstrated a role for O-glycosylation in blood clotting and immune system function [82]. Mutant mice had reduced plasma clotting factors and a concomitant increase in clotting time. Additionally, animals displayed decreased B cell homing to lymph nodes, the result of significant reductions in L-selectin ligands on high endothelial venules. The decreased neutrophil recruitment observed was the result of decreases in $\mathrm{E}$ - and $\mathrm{P}$-selectin ligands on these cells, resulting in an alteration in their adhesive properties. Alterations in germinal center formation via increased apoptosis of B cells normally present there resulted in decreased $\mathrm{IgG}$ production, indicating a crucial role for ppGalNAc-T1 in the regulation of $B$ cell maturation and antibody production. While the exact molecular mechanisms by which O-glycans mediate these effects remain to be determined, these studies highlight the importance of Olinked glycans in many tissues and cells involved in proper vascular function and humoral immunity.

\section{Conclusion}

Recent advances in deciphering the machinery controlling $\mathrm{O}$ glycosylation in many experimental systems described herein have aided our understanding of the in vivo role of mucin-type O-glycans. Continued efforts to elucidate the molecular role of O-glycosylation in both development and disease in many diverse organisms will highlight conserved processes in which glycosylation plays key regulatory roles, with the eventual goal of designing better strategies to improve human health.

Acknowledgments We would like to thank the many members of the community who have contributed to the work mentioned herein. We would like to thank Dr. Lawrence Tabak for carefully reading this manuscript. Our laboratory is supported by the Intramural Research Program of the NIDCR, NIH.

Open Access This article is distributed under the terms of the Creative Commons Attribution Noncommercial License which permits any noncommercial use, distribution, and reproduction in any medium, provided the original author(s) and source are credited.

\section{References}

1. Haltiwanger, R.S., Lowe, J.B.: Role of glycosylation in development. Annu. Rev. Biochem. 73, 491-537 (2004)

2. Ten Hagen, K.G., Fritz, T.A., Tabak, L.A.: All in the family: the UDP-GalNAc:polypeptide $N$-acetylgalactosaminyltransferases. Glycobiol. 13, 1R-16R (2003)

3. Hang, H.C., Bertozzi, C.R.: The chemistry and biology of mucin-type O-linked glycosylation. Bioorg. Med. Chem. 13, 5021-5034 (2005)

4. Ten Hagen, K.G., Tran, D.T., Gerken, T.A., Stein, D.S., Zhang, Z.: Functional characterization and expression analysis of members of the UDP-GalNAc:polypeptide $N$-acetylgalactosaminyltransferase family from Drosophila melanogaster. J. Biol. Chem. 278, 3503935048 (2003)

5. Schwientek, T., Bennett, E.P., Flores, C., Thacker, J., Hollmann, M., Reis, C.A., Behrens, J., Mandel, U., Keck, B., Schafer, M.A., Haselmann, K., Zubarev, R., Roepstorff, P., Burchell, J.M., Taylor-Papadimitriou, J., Hollingsworth, M.A., Clausen, H.: Functional conservation of subfamilies of putative UDP- $N$ acetylgalactosaminyltransferases in Drosophila, Caenorhabditis elegans, and mammals. J. Biol. Chem. 277, 22623-22638 (2002)

6. Tian, E., Ten Hagen, K.G.: Expression of the UDP-GalNAc: polypeptide $N$-acetylgalactosaminyltransferase family is spatially and temporally regulated during Drosophila development. Glycobiol. 16, 83-95 (2006)

7. Hagen, F.K., Nehrke, K.: cDNA cloning and expression of a family of UDP- $N$-acetyl-D-galactosamine:polypeptide $N$-acetylgalactosaminyltransferase sequence homologs from Caenorhabditis elegans. J. Biol. Chem. 273, 8268-8277 (1998)

8. Hagen, F.K., Layden, M., Nehrke, K., Gentile, K., Berbach, K., Tsao, C.C., Forsythe, M.: Mucin-type O-glycosylation in $C$. elegans is initiated by a family of glycosyltransferases. Trends Glycosci. Glycotechnol. 13, 463-479 (2001)

9. Zara, J., Hagen, F.K., Ten Hagen, K.G., van Wuyckhuyse, B.C., Tabak, L.A.: Cloning and expression of mouse UDP-GalNAc: polypeptide $N$-acetylgalactosaminyltransferase-T3. Biochem. Biophys. Res. Comm. 228, 38-44 (1996) 
10. Bennett, E.P., Hassan, H., Mandel, U., Hollingsworth, M.A., Akisawa, N., Ikematsu, Y., Merkx, G., van Kessel, A.G., Olofsson, S., Clausen, H.: Cloning and characterization of a close homologue of human UDP- $N$-acetyl-(-D-galactosamine:polypeptide $N$-acetylgalactosaminyltransferase-T3, designated Ga1Nac-T6. J. Biol. Chem. 274, 25362-25370 (1999)

11. Takeuchi, H., Kato, K., Hassan, H., Clausen, H., Irimura, T.: OGalNAc incorporation into a cluster acceptor site of three consecutive threonines. Distinct specificity of GalNAc-transferase isoforms. Eur. J. Biochem. 269, 6173-6183 (2002)

12. Wandall, H.H., Hassan, H., Mirgorodsksya, E., Kristensen, A.K., Roepstorff, P., Bennett, E.P., Nielsen, P.A., Hollingsworth, M.A., Burchell, J., Taylor-Papadimitriou, J., Clausen, H.: Substrate specificities of three members of the human UDP- $N$-acetyl-(-Dgalactosamine:polypeptide $\mathrm{N}$-acetylgalactosaminyltransferases family, GalNAc-T1, -T2, and -T3. J. Biol. Chem. 272, 2350323514 (1997)

13. Ten Hagen, K.G., Hagen, F.K., Balys, M.M., Beres, T.M., Van Wuyckhuyse, B., Tabak, L.A.: Cloning and expression of a novel, tissue specifically expressed member of the UDP-GalNAc: polypeptide $N$-acetylgalactosaminyltransferase family. J. Biol. Chem. 273, 27749-27754 (1998)

14. Nehrke, K., Hagen, F.K., Tabak, L.A.: Isoform-specific Oglycosylation by murine UDP-GaINAc:polypeptide $N$-acetylgalactosaminyltransferase-T3, in vivo. Glycobiol. 8, 367-371 (1998)

15. Ten Hagen, K.G., Tetaert, D., Hagen, F.K., Richet, C., Beres, T. M., Gagnon, J., Balys, M.M., Van Wuyckhuyse, B., Bedi, G.S., Degand, P., Tabak, L.A.: Characterization of a UDP-GalNAc: polypeptide $N$-acetylgalactosaminyltransferases that displays glycopeptide $\mathrm{N}$-acetylgalactosaminyltransferases activity. J. Biol. Chem. 274, 27867-27874 (1999)

16. Bennett, E.P., Hassan, H., Hollingsworth, M.A., Clausen, H.: A novel human UDP- $N$-acetyl-D-galactosamine:polypeptide $N$-acetylgalactosaminyltransferase, GalNac-T7, with specificity for partial GalNAc-glycosylated acceptor substrates. FEBS Lett. 460, 226-230 (1999)

17. Ten Hagen, K.G., Bedi, G.S., Tetaert, D., Kingsley, P.D., Hagen, F.K., Balys, M.M., Beres, T.M., Degand, P., Tabak, L.A.: Cloning and characterization of a ninth member of the UDP-GalNAc: polypeptide $\mathrm{N}$-acetylgalactosaminyltransferases family, ppGaNTase-T9. J. Biol. Chem. 276, 17395-17404 (2001)

18. Tetaert, D., Ten Hagen, K.G., Richet, C., Boersma, A., Gagnon, J., Degand, P.: Glycopeptide $N$-acetylgalactosaminytransferase specificities for O-glycosylated sites on MUC5AC mucin motif peptides. Biochem. J. 357, 313-320 (2001)

19. Kingsley, P.D., Ten Hagen, K.G., Maltby, K.M., Zara, J., Tabak, L.A.: Diverse spatial expression patterns of UDP-GalNAc:polypeptide $N$ acetylgalactosaminyltransferase family member mRNAs during mouse development. Glycobiol. 10, 1317-1323 (2000)

20. Ju, T., Cummings, R.D., Canfield, W.M.: Purification, characterization, and subunit structure of rat core $1 \mathrm{~b} 1,3$-galactosyltransferase. J. Biol. Chem. 277, 169-177 (2002)

21. Ju, T., Brewer, K., D’Souza, A., Cummings, R.D., Canfield, W. M.: Cloning and expression of human core 1 b1,3-galactosyltransferase. J. Biol. Chem. 277, 178-186 (2002)

22. Ju, T., Zheng, Q., Cummings, R.D.: Identification of core 1 Oglycan T-synthase from Caenorhabditis elegans. Glycobiol. 16, 947-958 (2006)

23. Muller, R., Hulsmeier, A.J., Altmann, F., Ten Hagen, K.G., Tiemeyer, M., Hennet, T.: Characterization of mucin-type core-1 b1-galactosyltransferase homologous enzymes in Drosophila melanogaster. FEBS J. 272, 4295-4305 (2005)

24. Ju, T., Cummings, R.D.: A unique molecular chaperone cosmc required for activity of the mammalian core 1 b1,3-galactosyltransferase. Proc. Natl. Acad. Sci. U. S. A. 99, 16613-16618 (2002)
25. Narimatsu, Y., Ikehara, Y., Iwasaki, H., Nonomura, C., Sato, T., Nakanishi, H., Narimatsu, H.: Immunocytochemical analysis for intracellular dynamics of C1GalT associated with molecular chaperone, Cosmc. Biochem. Biophys. Res. Commun. 366, 199-205 (2008)

26. Zhou, D., Berger, E.G., Hennet, T.: Molecular cloning of a human UDP-galactose:GlcNAcb1,3GalNAc b1,3 galactosyltransferase gene encoding an O-linked core3-elongation enzyme. Eur. J. Biochem. 263, 571-576 (1999)

27. Iwai, T., Inaba, N., Naundorf, A., Zhang, Y., Gotoh, M., Iwasaki, H., Kudo, T., Togayach, A., Ishizuka, Y., Nakanishi, H., Narimatsu, H.: Molecular cloning and characterization of a novel UDP-GlcNAc:GalNAc-peptide b 1,3- $N$-acetylglucosaminyltransferase (b 3Gn-T6), an enzyme synthesizing the core 3 structure of O-glycans. J. Biol. Chem. 277, 12802-12809 (2002)

28. Bierhuizen, M.F., Fukuda, M.: Expression cloning of a cDNA encoding UDP-GlcNAc:Gal beta 1-3-GalNAc-R (GlcNAc to GalNAc) beta 1-6GlcNAc transferase by gene transfer into $\mathrm{CHO}$ cells expressing polyoma large tumor antigen. Proc. Natl. Acad. Sci. U. S. A. 89, 9326-933 (1992)

29. Li, C.M., Adler, K.B., Cheng, P.W.: Mucin biosynthesis: molecular cloning and expression of bovine lung mucin core 2 $\mathrm{N}$-acetylglucosaminyltransferase cDNA. Am. J. Respir. Cell Mol. Biol. 18, 343-352 (1998)

30. Schwientek, T., Nomoto, M., Levery, S.B., Merkx, G., van Kessel, A.G., Bennett, E.P., Hollingsworth, M.A., Clausen, H.: Control of O-glycan branch formation. Molecular cloning of human cDNA encoding a novel b1, 6- $N$-acetylglucosaminlytransferase forming core 2 and core 4. J. Biol. Chem. 274, 4504-4512 (1999)

31. Yeh, J.C., Ong, E., Fukuda, M.: Molecular cloning and expression of a novel beta-1, 6- $N$-acetylglucosaminyltransferase that forms core 2, core 4, and I branches. J. Biol. Chem. 274, 3215-3221 (1999)

32. Schwientek, T., Yeh, J.C., Levery, S.B., Keck, B., Merkx, G., van Kessel, A.G., Fukuda, M., Clausen, H.: Control of O-glycan branch formation. Molecular cloning and characterization of a novel thymus-associated core 2 beta1, 6- $N$-acetylglucosaminyltransferase. J. Biol. Chem. 275, 11106-11113 (2000)

33. Fukuda, M.: Roles of mucin-type O-glycans synthesized by core2b1,6- $N$-acetylglucosaminyltransferase. Methods Enzymol. 416, 332-346 (2006)

34. Warren, C.E., Krizus, A., Partridge, E.A., Dennis, J.W.: Caenorhabditis elegans gly-1, a core 2/I $N$-acetylglucosaminyltransferase homologue, is a glucosyltransferase. Glycobiol. 12, 8G-9G (2002)

35. North, S.J., Koles, K., Hembd, C., Morris, H.R., Dell, A., Panin, V.M., Haslam, S.M.: Glycomic studies of Drosophila melanogaster embryos. Glycoconj. J. 23, 345-354 (2006)

36. Guérardel, Y., Balanzino, L., Maes, E., Leroy, Y., Coddeville, B., Oriol, R., Strecker, G.: The nematode Caenorhabditis elegans synthesizes unusual O-linked glycans: identification of glucosesubstituted mucin-type O-glycans and short chondroitin-like oligosaccharides. Biochem. J. 357, 167-182 (2001)

37. Ten Hagen, K.G., Tran, D.T.: A UDP-GalNAc:polypeptide $N$ acetylgalactosaminyltransferase is essential for viability in Drosophila melanogaster. J. Biol. Chem. 277, 22616-22622 (2002)

38. Xia, L., Ju, T., Westmuckett, A., An, G., Ivanciu, L., McDaniel, J. M., Lupu, F., Cummings, R.D., McEver, R.P.: Defective angiogenesis and fatal embryonic hemorrhage in mice lacking core 1derived O-glycans. J. Cell Biol. 164, 451-459 (2004)

39. Alexander, W., Viney, E.M., Zhang, J., Metcalf, D., Kauppi, M., Hyland, C.D., Carpinelli, M.R., Stevenson, W., Croker, B.A., Hilton, A.A., Ellis, S., Selan, C., Nandurkar, H.H., Goodnow, C.C., Kile, B.T., Nicola, N.A., Roberts, A.W., Hilton, D.J.: Thrombocytopenia and kidney disease in mice with a mutation in the C1galt1 gene.. Proc. Natl. Acad. Sci. U. S. A. 103, 16442-16447 (2006)

40. Doyonnas, R., Kershaw, D.B., Duhme, C., Merkens, H., Chelliah, S., Graf, T., McNagny, K.M.: Anuria, omphalocele, and perinatal 
lethality in mice lacking the CD34-related protein podocalyxin. J. Exp. Med. 194, 13-27 (2001)

41. Tian, E., Ten Hagen, K.G.: O-linked glycan expression during Drosophila development. Glycobiol. 17, 820-827 (2007)

42. Tian, E., Ten Hagen, K.G.: A UDP-GalNAc: polypeptide $N$ acetylgalactosaminyltransferase is required for epithelial tube formation. J. Biol. Chem. 282, 606-614 (2007)

43. Alfalah, M., Jacob, R., Preuss, U., Zimmer, K.P., Naim, H., Naim, H.Y.: O-linked glycans mediate apical sorting of human intestinal survase-isomaltase through association with lipid rafts. Curr. Biol. 9, 593-596 (1999)

44. Altschuler, Y., Kinlough, C.L., Poland, P.A., Bruns, J.B., Apodaca, G., Weisz, O.A., Hughey, R.P.: Clathrin-mediated endocytosis of MUC1 is modulated by its glycosylation state. Mol. Biol. Cell. 11, 819-831 (2000)

45. Yeaman, C., Le Gall, A.H., Baldwin, A.N., Monlauzeur, L., Le Bivic, A., Rodriguez-Boulan, E.: The O-glycosylated stalk domain is required for apical sorting of neurotrophin receptors in polarized MDCK cells. J. Cell. Biol. 139, 929-940 (1997)

46. Huet, G., Hennebicq-Reig, S., de Bolos, C., Ulloa, F., Lesuffleur, T., Barbat, A., Carriere, V., Kim, I., Real, F.X., Delannoy, P., Zweibaum, A.: GalNAc-alpha-O-benzyl inhibits NeuAcapha2-3 glycosylation and blocks the intracellular transport of apical glycoproteins and mucus in differentiated HT-29 cells. J. Cell. Biol. 141, 1311-1322 (1998)

47. Liebl, F.L., Featherstone, D.E.: Genes involved in Drosophila glutamate receptor expression and localization. BMC. Neurosci. 28, 44-55 (2005)

48. Potter, B.A., Hughey, R.P., Weisz, O.A.: Role of N- and Oglycans in polarized biosynthetic sorting. Am. J. Physiol. Cell Physiol. 290, C1-C10 (2006)

49. Funes, M., Miller, J.K., Lai, C., Carraway 3rd, K.L., Sweeney, C.: The mucin Muc4 potentiates neuregulin signaling by increasing the cell-surface populations of ErbB2 and ErbB3. J. Biol. Chem. 281, 19310-19319 (2006)

50. Herr, P., Korniychuk, G., Yamamoto, Y., Grubisic, K., Oelgeschlager, M.: Regulation of TGF- $\beta$ signaling by $\mathrm{N}$-acetylgalactosaminyltransferase-like 1. Development 135, 1813-1822 (2008)

51. Topaz, O., Shurman, D.L., Bergman, R., Indelman, M., Ratajczak, P., Mizrachi, M., Khamaysi, Z., Behar, D., Petronius, D., Friedman, V., Zelikovic, I., Raimer, S., Metzker, A., Richard, G., Sprecher, E.: Mutations in GALNT3, encoding a protein involved in O-linked glycosylation, cause familial tumoral calcinosis. Nat. Genet. 36, 579-581 (2004)

52. Ichikawa, S., Guigonis, V., Imel, E.A., Courouble, M., Heissat, S., Henley, J.D., Sorenson, A.H., Petit, B., Lienhardt, A., Econs, M. J.: Novel GALNT3 mutations causing hyperostosis-hyperphosphatemia syndrome result in low intact fibroblast growth factor 23 concentrations. J. Clin. Endocrinol. Metab. 92, 1943-1947 (2007)

53. Barbieri, A.M., Filopanti, M., Bua, G., Beck-Peccoz, P.: Two novel nonsense mutations in GALNT3 gene are responsible for familial tumoral calcinosis. J. Hum. Genet. 52, 464-468 (2007)

54. Benet-Pagès, A., Orlik, P., Strom, T.M., Lorenz-Depiereux, B.: An FGF23 missense mutation causes familial tumoral calcinosis with hyperphosphatemia. Hum. Mol. Genet. 14, 385-390 (2005)

55. Frishberg, Y., Ito, N., Rinat, C., Yamazaki, Y., Feinstein, S., Urakawa, I., Navon-Elkan, P., Becker-Cohen, R., Yamashita, T., Araya, K., Igarashi, T., Fujita, T., Fukumoto, S.: Hyperostosishyperphosphatemia syndrome: a congenital disorder of $\mathrm{O}$ glycosylation associated with augmented processing of fibroblast growth factor 23. J. Bone Miner. Res. 22, 235-242 (2007)

56. Kato, K., Jeanneau, C., Tarp, M.A., Benet-Pages, A., LorenzDepiereux, B., Bennett, E.P., Mandel, U., Strom, T.M., Clausen, H.: Polypeptide GalNAc-transferase T3 and familial tumoral calcinosis. Secretion of fibroblast growth factor 23 requires Oglycosylation. J. Biol. Chem. 281, 18370-18377 (2006)
57. Ju, T., Cummings, R.D.: Protein glycosylation: chaperone mutation in Tn syndrome. Nature. 437, 1252 (2005)

58. Barratt, J., Feehally, J., Smith, A.C.: Pathogenesis of IgA nephropathy. Semin. Nephrol. 24, 197-217 (2004)

59. Iwase, H., Tanaka, A., Hiki, Y., Kokubo, T., Sano, T., IshiiKarakasa, I., Hisatani, K., Kobayashi, Y., Hotta, K.: Analysis of the microheterogeneity of the IgA1 hinge glycopeptide having multiple O-linked oligosaccharides by capillary electrophoresis. Anal. Biochem. 288, 22-7 (2001)

60. Hiki, Y., Kokubo, T., Iwase, H., Masaki, Y., Sano, T., Tanaka, A., Toma, K., Hotta, K., Kobayashi, Y.: Underglycosylation of IgA1 hinge plays a certain role for its glomerular deposition in IgA nephropathy. J. Am. Soc. Nephrol. 10, 760-769 (1999)

61. Hiki, Y., Odani, H., Takahashi, M., Yasuda, Y., Nishimoto, A., Iwase, H., Shinzato, T., Kobayashi, Y., Maeda, K.: Mass spectrometry proves under-O-glycosylation of glomerular IgA1 in IgA nephropathy. Kidney Int. 59, 1077-1085 (2001)

62. Renfrow, M.B., Mackay, C.L., Chalmers, M.J., Julian, B.A., Mestecky, J., Kilian, M., Poulsen, K., Emmett, M.R., Marshall, A. G., Novak, J.: Analysis of O-glycan heterogeneity in IgA1 myeloma proteins by Fourier transform ion cyclotron resonance mass spectrometry: implications for IgA nephropathy. Anal. Bioanal. Chem. 389, 1397-1407 (2007)

63. Tomana, M., Novak, J., Julian, B.A., Matousovic, K., Konecny, K., Mestecky, J.: Circulating immune complexes in IgA nephropathy consist of IgA1 with galactose-deficient hinge region and antiglycan antibodies. J. Clin. Invest. 104, 73-81 (1999)

64. Coppo, R., Amore, A.: Aberrant glycosylation in IgA nephropathy. Kidney Int. 65, 1544-1547 (2004)

65. Hiki, Y., Tanaka, A., Kokubo, T., Iwase, H., Nishikido, J., Hotta, K., Kobayashi, Y.: Analyses of IgA1 hinge glycopeptides in IgA nephropathy by matrix-assisted laser desorption/ionization time-offlight mass spectrometry. J. Am. Soc. Nephrol. 9, 577-582 (1998)

66. Allen, A.C., Bailey, E.M., Brenchley, P.E., Buck, K.S., Barratt, J., Feehally, J.: Mesangial IgA1 in IgA nephropathy exhibits aberrant O-glycosylation: observations in three patients. Kidney Int. 60, 969-973 (2001)

67. Qin, W., Zhong, X., Fan, J.M., Zhang, Y.J., Liu, X.R., Ma, X.Y.: External suppression causes the low expression of the Cosmc gene in IgA nephropathy. Nephrol. Dial. Transplant. 23, 1608-1614 (2008) doi:10.1093/ndt/gfm781

68. Buck, K.S., Smith, A.C., Molyneux, K., El-Barbary, H., Feehally, J., Barratt, J.: B-cell O-galactosyltransferase activity, and expression of O-glycosylation genes in bone marrow in IgA nephropathy. Kidney Int. 73, 1128-1136 (2008) doi:10.1038/sj.ki.5002748

69. Kathiresan S., Melander O., Guiducci C., Surti A., Burtt N.P., Rieder M.J., Cooper G.M., Roos C., Voight B.F., Havulinna A.S., Wahlstrand B., Hedner T., Corella D., Tai E.S., Ordovas J.M., Berglund G., Vartiainen E., Jousilahti P., Hedblad B., Taskinen M. R., Newton-Cheh C., Salomaa V., Peltonen L., Groop L., Altshuler D.M., Orho-Melander M.: Six new loci associated with blood low-density lipoprotein cholesterol, high-density lipoprotein cholesterol or triglycerides in humans. Nature Genetics. 40, 189197 (2008)

70. Willer C.J., Sanna S., Jackson A.U., Scuteri A., Bonnycastle L.L., Clarke R., Heath S.C., Timpson N.J., Najjar S.S., Stringham H. M., Strait J., Duren W.L., Maschio A., Busonero F., Mulas A., Albai G., Swift A.J., Morken M.A., Narisu N., Bennett D., Parish S., Shen H., Galan P., Meneton P., Hercberg S., Zelenika D., Chen W.M., Li Y., Scott L.J., Scheet P.A., Sundvall J., Watanabe R.M., Nagaraja R., Ebrahim S., Lawlor D.A., Ben-Shlomo Y., DaveySmith G., Shuldiner A.R., Collins R., Bergman R.N., Uda M., Tuomilehto J., Cao A., Collins F.S., Lakatta E., Lathrop G.M., Boehnke M., Schlessinger D., Mohlke K.L.: Abecasis GR. Newly identified loci that influence lipid concentrations and risk of coronary artery disease. Nature Genetics. 40, 161-169 (2008) 
71. Kim, Y.S., Gum Jr., J., Brockhausen, L.: Mucin glycoproteins in neoplasia. Glycoconj. J. 13, 693-707 (1996)

72. Kim, Y.J., Varki, A.: Perspectives on the significance of altered glycosylation of glycoproteins in cancer. Glycoconj. J. 14, 569-576 (1997)

73. Springer, G.F.: Immunoreactive $\mathrm{T}$ and $\mathrm{Tn}$ epitopes in cancer diagnosis, prognosis, and immunotherapy. J. Mol. Med. 75, 594602 (1997)

74. Ono, M., Hakomori, S.: Glycosylation defining cancer cell motility and invasiveness. Glycoconj. J. 20, 71-78 (2004)

75. Iwai, T., Kudo, T., Kawamoto, R., Kubota, T., Togayachi, A., Hiruma, T., Okada, T., Kawamoto, T., Morozumi, K., Narimatsu, H.: Core 3 synthase is down-regulated in colon carcinoma and profoundly suppresses the metastatic potential of carcinoma cells. Proc. Natl. Acad. Sci. U. S. A. 102, 4572-4577 (2005)

76. An, G., Wei, B., Xia, B., McDaniel, J.M., Ju, T., Cummings, R.D., Braun, J., Xia, L.: Increased susceptibility to colitis and colorectal tumors in mice lacking core 3-derived O-glycans. J. Exp. Med. 204, 1417-1429 (2007)

77. Ellies, L.G., Tsuboi, S., Petryniak, B., Lowe, J.B., Fukuda, M., Marth, J.D.: Core 2 oligosaccharide biosynthesis distinguishes between selectin ligands essential for leukocyte homing and inflammation. Immunity. 9, 881-890 (1998)

78. Broide, D.H., Miller, M., Castaneda, D., Nayar, J., Cho, J.Y., Roman, M., Ellies, L.G., Sriramarao, P.: Core 2 oligosaccharides mediate eosinophil and neutrophil peritoneal but not lung recruitment. Am. J. Physiol. Lung Cell. Mol. Physiol. 282, L259-L266 (2002)

79. Mitoma, J., Bao, X., Petryanik, B., Schaerli, P., Gauguet, J.M., Yu, S.Y., Kawashima, H., Saito, H., Ohtsubo, K., Marth, J.D., Khoo, K.H., von Andrian, U.H., Lowe, J.B., Fukuda, M.: Critical functions of N-glycans in L-selectin-mediated lymphocyte homing and recruitment. Nat. Immunol. 8, 409-418 (2007)

80. Homeister, J.W., Thall, A.D., Petryniak, B., Malý, P., Rogers, C. E., Smith, P.L., Kelly, R.J., Gersten, K.M., Askari, S.W., Cheng, G., Smithson, G., Marks, R.M., Misra, A.K., Hindsgaul, O., von Andrian, U.H., Lowe, J.B.: The alpha(1,3)fucosyltransferases FucT-IV and FucT-VII exert collaborative control over selectindependent leukocyte recruitment and lymphocyte homing. Immunity. 15, 115-126 (2001)

81. Priatel, J.J., Chui, D., Hiraoka, N., Simmons, C.J., Richardson, K.B., Page, D.M., Fukuda, M., Varki, N.M., Marth, J.D.: The ST3Gal-I sialyltransferase controls CD8+ T lymphocyte homeostasis by modulating O-glycan biosynthesis. Immunity. 12, 273-283 (2000)

82. Tenno, M., Ohtsubo, K., Hagen, F.K., Ditto, D., Zarbock, A., Schaerli, P., von Andrian, U.H., Ley, K., Le, D., Tabak, L.A., Marth, J.D.: Initiation of protein $\mathrm{O}$ glycosylation by the polypeptide GalNAcT-1 in vascular biology and humoral immunity. Mol. Cell. Biol. 27, 8783-8796 (2007)

83. Homa, F.L., Hollander, T., Lehman, D.J., Thomsen, D.R., Elhammer, A.P.: Isolation and expression of a cDNA clone encoding a bovine UDP-GalNAc:polypeptide N-acetylgalactosaminyltransferase. J. Biol. Chem. 268, 12609-12616 (1993)

84. Hagen, F.K., VanWuyckhuyse, B., Tabak, L.A.: Purification, cloning, and expression of a bovine UDP-GalNAc:polypeptide N-Acetylgalactosaminyltransferase. J. Biol. Chem. 268, 18960 18965 (1993)

85. Hagen, F.K., Gregoire, C.A., Tabak, L.A.: Cloning and sequence homology of a rat UDP-GalNAc:polypeptide N-acetylgalactosaminyltransferase. Glycoconj. J. 12, 901-909 (1995)

86. White, T., Bennett, E.P., Takio, K., Sørensen, T., Bonding, N., Clausen, H.: Purification and cDNA cloning of a human UDP-N-
acetyl-alpha-D-galactosamine:polypeptide $\mathrm{N}$-acetylgalactosaminyltransferase. J. Biol. Chem. 270, 24156-24165 (1995)

87. Hagen, F.K., Ten Hagen, K.G., Beres, T.M., Balys, M.M., VanWuyckhuyse, B.C., Tabak, L.A.: cDNA cloning and expression of a novel UDP-N-acetyl-D-galactosamine:polypeptide N-acetylgalactosaminyltransferase. J. Biol. Chem. 272, 13843-13848 (1997)

88. Yoshida, A., Hara, T., Ikenaga, H., Takeuchi, M.: Cloning and expression of a porcine UDP-GalNAc: polypeptide N-acetylgalactosaminyl transferase. Glycoconj. J. 12, 824-828 (1995)

89. Bennett, E.P., Hassan, H., Clausen, H.: cDNA cloning and expression of a novel human UDP-N-acetyl-alpha-D-galactosamine. Polypeptide N-acetylgalactosaminyltransferase, GalNAc-t3. J. Biol. Chem. 271, 17006-17012 (1996)

90. Bennett, E.P., Hassan, H., Mandel, U., Mirgorodskaya, E., Roepstorff, P., Burchell, J., Taylor-Papadimitriou, J., Hollingsworth, M.A., Merkx, G., van Kessel, A.G., Eiberg, H., Steffensen, R., Clausen, H.: Cloning of a human UDP-N-acetyl-alpha-DGalactosamine:polypeptide N-acetylgalactosaminyltransferase that complements other GalNAc-transferases in complete O-glycosylation of the MUC1 tandem repeat. J. Biol. Chem. 273, 30472-30481 (1998)

91. White, K.E., Lorenz, B., Evans, W.E., Meitinger, T., Strom, T.M., Econs, M.J.: Molecular cloning of a novel human UDP-GalNAc: polypeptide N-acetylgalactosaminyltransferase, GalNAc-T8, and analysis as a candidate autosomal dominant hypophosphatemic rickets (ADHR) gene. Gene. 246, 347-356 (2000)

92. Toba, S., Tenno, M., Konishi, M., Mikami, T., Itoh, N., Kurosaka, A.: Brainspecific expression of a novel human UDP-GalNAc: polypeptide N-acetylgalactosaminyltransferase (GalNAc-T9). Biochim. Biophys. Acta. 1493, 264-268 (2000)

93. Zhang, Y., Iwasaki, H., Wang, H., Kudo, T., Kalka, T.B., Hennet, T., Kubota, T., Cheng, L., Inaba, N., Gotoh, M., Togayachi, A., Guo, J., Hisatomi, H., Nakajima, K., Nishihara, S., Nakamura, M., Marth, J.D., Narimatsu, H.: Cloning and characterization of a new human UDP-N-acetyl-alpha-D-galactosamine:polypeptide $\mathrm{N}$-acetylgalactosaminyltransferase, designated pp-GalNAc-T13, that is specifically expressed in neurons and synthesizes GalNAc alpha-serine/threonine antigen. J. Biol. Chem. 278, 573-584 (2003)

94. Cheng, L., Tachibana, K., Zhang, Y., Guo, J., Kahori Tachibana, K., Kameyama, A., Wang, H., Hiruma, T., Iwasaki, H., Togayachi, A., Kudo, T., Narimatsu, H.: Characterization of a novel human UDP-GalNAc transferase, pp-GalNAc-T10. FEBS Lett. 531, 115$121(2002)$

95. Guo, J.M., Zhang, Y., Cheng, L., Iwasaki, H., Wang, H., Kubota, T., Tachibana, K., Narimatsu, H.: Molecular cloning and characterization of a novel member of the UDP-GalNAc:polypeptide Nacetylgalactosaminyltransferase family, pp-GalNAc-T12. FEBS Lett. 524, 211-218 (2002)

96. Hennet, T., Hagen, F.K., Tabak, L.A., Marth, J.D.: T-cell-specific deletion of a polypeptide $\mathrm{N}$-acetylgalactosaminyl-transferase gene by site-directed recombination. Proc. Natl. Acad. Sci. USA. 92, 12070-12074 (1995)

97. Wang, H., Tachibana, K., Zhang, Y., Iwasaki, H., Kameyama, A., Cheng, L., Guo, J., Hiruma, T., Togayachi, A., Kudo, T., Kikuchi, N., Narimatsu, H.: Cloning and characterization of a novel UDP-GalNAc: polypeptide N-acetylgalactosaminyltransferase, pp-GalNAc-T14. Biochem. Biophys. Res. Commun. 300, 738-744 (2003)

98. Cheng, L., Tachibana, K., Iwasaki, H., Kameyama, A., Zhang, Y., Kubota, T., Hiruma, T., Tachibana, K., Kudo, T., Guo, J.M., Narimatsu, H.: Characterization of a novel human UDP-GalNAc transferase, pp-GalNAc-T15. FEBS Lett. 566, 17-24 (2004) 